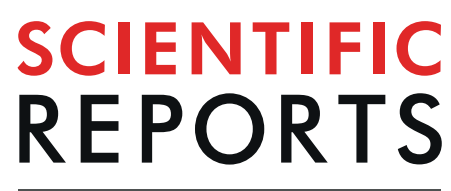

natureresearch

\title{
Characterization of chitosan/ alginate/lovastatin nanoparticles and investigation of their toxic effects in vitro and in vivo
}

\author{
Hoang Thai ${ }^{1,5^{*}}$, Chinh Thuy Nguyen ${ }^{1}$, Loc Thi Thach ${ }^{2}$, Mai Thi Tran ${ }^{1}$, Huynh Duc Mai ${ }^{1}$, \\ Trang Thi Thu Nguyen ${ }^{1}$, Giang Duc Le ${ }^{2}$, Mao Van Can ${ }^{4}$, Lam Dai Tran ${ }^{1,5}$, Giang Long Bach ${ }^{6}$, \\ Kavitha Ramadass ${ }^{7}$, C. I. Sathish ${ }^{7}$ \& Quan Van Le ${ }^{3 *}$
}

In this study, chitosan and alginate were selected to prepare alginate/chitosan nanoparticles to load the drug lovastatin by the ionic gelation method. The synthesized nanoparticles loaded with drug were characterized by Fourier transform infrared spectroscopy (FT-IR), scanning electron microscopy (SEM), laser scattering and differential scanning calorimetry (DSC) methods. The FTIR spectrum of the alginate/chitosan/lovastatin nanoparticles showed that chitosan and alginate interacted with lovastatin through hydrogen bonding and dipolar-dipolar interactions between the $\mathrm{C}-\mathrm{O}, \mathrm{C}=\mathrm{O}$, and $\mathrm{OH}$ groups in lovastatin, the $\mathrm{C}-\mathrm{O}, \mathrm{NH}$, and $\mathrm{OH}$ groups in chitosan and the $\mathrm{C}-\mathrm{O}, \mathrm{C}=\mathrm{O}$, and $\mathrm{OH}$ groups in alginate. The laser scattering results and SEM images indicated that the alginate/chitosan/lovastatin nanoparticles have a spherical shape with a particle size in the range of $50-80 \mathrm{~nm}$. The DSC diagrams displayed that the melting temperature of the alginate/chitosan/lovastatin nanoparticles was higher than that of chitosan and lower than that of alginate. This result means that the alginate and chitosan interact together, so that the nanoparticles have a larger crystal degree when compared with alginate and chitosan individually. Investigations of the in vitro lovastatin release from the alginate/chitosan/ lovastatin nanoparticles under different conditions, including different alginate/chitosan ratios, different solution $\mathrm{pH}$ values and different lovastatin contents, were carried out by ultraviolet-visible spectroscopy. The rate of drug release from the nanoparticles is proportional to the increase in the solution $\mathrm{pH}$ and inversely proportional to the content of the loaded lovastatin. The drug release process is divided into two stages: a rapid stage over the first $10 \mathrm{hr}$, then the release becomes gradual and stable. The Korsmeyer-Peppas model is most suitable for the lovastatin release process from the alginate/chitosan/lovastatin nanoparticles in the first stage, and then the drug release complies with other models depending on solution $\mathrm{pH}$ in the slow release stage. In addition, the toxicity of alginate/ chitosan/lovastatin (abbreviated ACL) nanoparticles was sufficiently low in mice in the acute toxicity test. The $\mathrm{LD}_{50}$ of the drug was higher than $5000 \mathrm{mg} / \mathrm{kg}$, while in the subchronic toxicity test with treatments of $100 \mathrm{mg} / \mathrm{kg}$ and $300 \mathrm{mg} / \mathrm{kg}$ ACL nanoparticles, there were no abnormal signs, mortality, or toxicity in general to the function or structure of the crucial organs. The results show that the ACL nanoparticles are safe in mice and that these composite nanoparticles might be useful as a new drug carrier.

\footnotetext{
${ }^{1}$ Institute for Tropical Technology, Vietnam Academy of Science and Technology, 18, Hoang Quoc Viet, Cau Giay, Hanoi, 100000, Vietnam. ${ }^{2}$ Vinh, University, 182 Le Duan, Vinh, Nghe An, 460000, Vietnam. ${ }^{3}$ Department of Functional Exploration, Military Hospital 103, 261 Phung Hung, Phuc La, Ha Dong, Hanoi, 100000, Vietnam. ${ }^{4}$ Department of Pathophysiology, Vietnam Military Medical University, 160 Phung Hung, Phuc La, Ha Dong, Hanoi, 100000, Vietnam. ${ }^{5}$ Graduate University of Science and Technology, Vietnam Academy of Science and Technology, 18 Hoang Quoc Viet, Cau Giay, Hanoi, 100000, Vietnam. ${ }^{6}$ NTT Institute of High Technology, Nguyen Tat Thanh University, 300A Nguyen Tat Thanh, District 4, Ho Chi Minh City, 700000, Vietnam. ${ }^{7}$ Global Innovative Center for Advanced Nanomaterials, Faculty of Engineering and Built Environment, The University of Newcastle, Callaghan, 2308, NSW, Australia. *email: hoangth@itt.vast.vn; levanquan2002@yahoo.com
} 
Currently, for the treatment of obesity (due to cholesterol in the blood exceeding the recommended limit) and cardiovascular disease, lovastatin is a commonly used drug that is effective and harmless. However, its applications are limited because of the low bioavailability in the major cycle and short half-life (approximately $3 \mathrm{hr}$ ), etc. Therefore, using polymer composites to load lovastatin can help to control the drug release ability to overcome the limitations of lovastatin in the treatment of the abovementioned diseases. The physical interactions between the polymers and lovastatin (hydrogen bonding, dipole-dipole interactions, etc.), facilitate the absorption and distribution of lovastatin to more easily control its release.

There are reports on the synthesis of polymer composites based on chitosan and polycaprolactone that have been used as carriers for lovastatin. These investigations mainly reported lovastatin release and established a suitable kinetic equation for drug release in solutions with different $\mathrm{pH}$ values ${ }^{1-5}$. It has been reported that lovastatin/ polymer nanoparticles could be effective in sustaining drug release for a prolonged period ${ }^{3}$.

Recently, interest in investigating polymer nanoparticles made from alginate and chitosan as drug carriers has been increasing due to their good adhesion, biodegradability, and biocompatibility ${ }^{6-11}$. Alginate particles are quite sensitive to $\mathrm{pH}$, swelling in alkaline solutions and shrinking in acidic solutions.

When a drug is coated with alginate, the drug will be protected from the effects of the gastric acid environment and be deliver directly into the intestine. Alginate particles could be the best suitable drug carriers for oral drug manufacturing. However, alginate is hydrophilic, and it is difficult to arrange alginate particles in an oil-water phase during the preparation process, leading to unstable emulsions. Therefore, alginate particles are mixed with chitosan to improve the hydrophilic properties of alginate but still retain the biological compatibility and $\mathrm{pH}$ sensitivity of alginate ${ }^{12}$. It is widely known that chitosan has high biodegradability and biocompatibility, and the amino groups of the chitosan molecules can interact with cations to form a cationic polymer and easily create complexes or nanoparticles in water to carry drug molecules. A porous structure and large specific surface area help chitosan load drugs with high capacity ${ }^{13}$. The combination of the carboxyl groups of alginate and the protonated amino groups of chitosan can form a polymer-electrolyte complex (PEC). The formation of the PEC limits the disadvantages of chitosan, such as its poor mechanical durability and unstable structure after implantation/ transplantation, hydrophobicity, and reduced moisture stability while retaining the biological activity of the material, leading to the formation of new materials with better properties and the ability to control drug and protein release more easily ${ }^{14,15}$. Alginate-chitosan microspheres and nanospheres have been synthesized by an emulsion technique, suspension or ionic gelation method and have been applied to load model drugs, such as rifampicin ${ }^{7}$, nifedipine ${ }^{8}, 5$-fluorouracil ${ }^{9}$, curcumin diethyl disuccinate ${ }^{11}$, insulin $^{16}$, ampicillin ${ }^{17}$, curcumin $^{18}$, verapamil ${ }^{19}$, tri- $^{\text {, }}$ metazidine hydrochloride $(\mathrm{TH})^{20}$, doxorubicin and paclitaxel $^{21}$, and paclitaxel ${ }^{22}$. The obtained results indicated that polymers are required to control the drugs in solutions of different $\mathrm{pH}$ values.

In our previous papers, alginate/chitosan polymer blend films (with an alginate/chitosan ratio of 8/2) carrying lovastatin (10, 20 and $30 \mathrm{wt}$. $\%$ calculated by comparison with the total alginate and chitosan weight) or ginsenoside Rb1 were extracted from Vietnamese Panax pseudoginseng $(5,10,15$ and 20 wt.\% calculated by comparison with the total alginate and chitosan weight) and prepared by the solution method at room temperature ${ }^{23,24}$. The results demonstrated that the alginate/chitosan films contributed to the controlled release of lovastatin and ginsenoside $\mathrm{Rb} 1$ from the alginate/chitosan film-loaded drugs at various solution $\mathrm{pH}$ values.

Published papers have only focused on the preparation of micro- and nanosized polymer composites based on alginate and chitosan carrying drugs as well as the drug release in vitro and drug release kinetics in different $\mathrm{pH}$ solutions. However, there have been no reports thus far on the fabrication of alginate (AG)/chitosan (CS) particles on the nanoscale carrying lovastatin by ionic gelation methods and investigation into their special properties. Therefore, this study concentrated on the preparation of alginate/chitosan/lovastatin nanoparticles using an ionic gelation method and investigation of the interactions between alginate and lovastatin, and chitosan and lovastatin, and the effects of the alginate/chitosan (AG/CS) ratio on the distribution and properties of the alginate/chitosan/lovastatin nanoparticles. In addition, the in vitro lovastatin release and drug release kinetics from the alginate/chitosan/lovastatin (ACL) nanoparticles in different $\mathrm{pH}$ solutions are considered and discussed. An acute toxicity evaluation of the alginate/chitosan/lovastatin nanoparticles was carried out in vivo in adult healthy Swiss mice. The suitable AG/CS ratio of $6.5 / 3$ (wt.\%/wt.\%) was best for the preparation of the ACL nanoparticles by the ionic gelation method. The ACL nanoparticles formed successfully in the range of 50-100 nm. Our in vivo results show that the ACL nanoparticles are safe, nontoxic and might be applied to lower serum cholesterol in animal models as well as humans.

\section{Experimental}

Materials and methods. Sodium alginate (AG) powder, viscosity 300-500 mPa.s; chitosan (CS) powder with deacetylation degree $>75-85 \%$, polymer density index $1.61 \times 10^{5} \mathrm{Da}$; and lovastatin (LS) powder, purity $\geq 98.0 \%$ were products of Sigma Aldrich Co. (St. Louis, MO $63103 \mathrm{USA}$ ). KCl, $\mathrm{NaOH}, \mathrm{KH}_{2} \mathrm{PO}_{4}, \mathrm{HCl}$ (37 wt $\%$ ), ethanol, and acetic acid (purity 99.5\%) were analytical reagents that were used as received without further purification.

Preparation of AG/CS/LS nanoparticles. The AG/CS/LS nanoparticles were prepared by ionic gelation according to the following steps: First, AG was dissolved in distilled water until a solution was formed before the addition of $\mathrm{CaCl}_{2}$ to increase the viscosity of the solution (solution 1). In addition, CS was dissolved in $1 \%$ acetic acid solution (solution 2), while LS was dissolved in ethanol (solution 3). Next, solution 1 was added dropwise to solution 2 and stirred in an ultrasonic bath to form a uniform solution. Thereafter, solution 3 was poured into the mixture of solution 1 and solution 2 and then ultrasonicated five times for 5 mins. Finally, the mixed solution was centrifuged at $4^{\circ} \mathrm{C}$ before lyophilization in a FreeZone 2.5 machine (Labconco, USA). The ratios of AG, CS, LS, and the coding of prepared samples are presented in Table 1. 


\begin{tabular}{|l|l|l|l|c|}
\hline AG (wt.\%) & CS (wt.\%) & LS (wt.\%) & Sample code & d (nm) $( \pm$ S.D.) \\
\hline 60.6 & 30.4 & 9.0 & AC6/3-L10 & $900.8 \pm 101.1$ \\
\hline 62.2 & 28.8 & 9.0 & AC6.5/3-L10 & $86.2 \pm 3.7$ \\
\hline 63.6 & 27.3 & 9.0 & AC7/3-L10 & $220.2 \pm 17.5$ \\
\hline 57.0 & 26.3 & 16.7 & AC6.5/3-L20 & $91.3 \pm 10.0$ \\
\hline 52.6 & 24.3 & 23.1 & AC6.5/3-L30 & $490.0 \pm 18.8$ \\
\hline
\end{tabular}

Table 1. The ratios of AG, CS and LS and the signature and diameter (d) the of prepared samples.

Characterization. The mean diameter and size distribution of the nanoparticles were measured by a Zetasizer Ver 6.20 particle size analyzer (Malvern Instruments Ltd.). Fourier transform infrared spectroscopy (FTIR) spectra of the ACL nanoparticles were recorded on a Nicolet/Nexus 670 spectrometer (USA) at room temperature with 32 scans at $8 \mathrm{~cm}^{-1}$ resolution and wavenumbers ranging from 400 to $4000 \mathrm{~cm}^{-1}$. Field emission scanning electron microscopy (FESEM) images of the LS and ACL nanoparticles were conducted using an S-4800 field emission scanning electron microscope (Hitachi). The thermal properties of the LS, AG, CS and ACL nanoparticles were determined on a DSC-60 thermogravimetric analyzer (Shimadzu) under an argon atmosphere from room temperature to $600^{\circ} \mathrm{C}$ at a heating rate of $10^{\circ} \mathrm{C} / \mathrm{min}$.

In vitro drug release study. The in vitro LS release tests were carried out on ACL nanoparticles as follows: $15 \mathrm{mg}$ of each sample was immersed in $100 \mathrm{ml}$ of phosphate-buffered saline (PBS) (pH 6.5 and 7.4), $\mathrm{HCl} / \mathrm{KCl}$ buffer solution ( $\mathrm{pH}$ 2) or acetic acid/sodium acetate buffer solution $\mathrm{pH}(4.5)$ at $37^{\circ} \mathrm{C}$ and placed in an incubated shaker at $120 \mathrm{rpm}$. Over $30 \mathrm{hr}$ at predetermined time intervals, $5 \mathrm{ml}$ aliquots were withdrawn, and the concentration of LS released was monitored by a UV spectrophotometer (CINTRA 40, GBC, USA). The dissolution medium was replaced with fresh solution to maintain the total volume. The LS release percent can be determined by the following equation:

$$
\text { Drug release }[\%]=\mathrm{C}_{(\mathrm{t})} / \mathrm{C}_{(0)} \times 100
$$

where $\mathrm{C}_{(0)}$ and $\mathrm{C}_{(\mathrm{t})}$ represent the amount of LS loaded and the amount of drug released at time $\mathrm{t}$, respectively. All studies were performed in triplicate.

Drug release kinetic study. According to the review literature, there are different types of drug release kinetics and mechanisms based on the polymer matrix. Drug release from a polymer matrix usually implies water penetration in the matrix, hydration, swelling, diffusion of the dissolved drug, and/or erosion of the gelatinous layer. It is worth mentioning that the release mechanism of a drug depends on the drug dose, investigation of the solution $\mathrm{pH}$, and the nature of the drug and polymer used. Recently, the most probable kinetics have been used for drug release, as depicted below ${ }^{1,2,20}$ :

Zero-order kinetics

$$
\mathrm{W}_{\mathrm{t}}=\mathrm{W}_{0}+\mathrm{k}_{1} \mathrm{t}
$$

First-order kinetics

$$
\log C_{t}=\log C_{0}-k_{2} t / 2.303
$$

Hixson-Crowell's cube-root equation (erosion model)

$$
(100-\mathrm{W})^{1 / 3}=100^{1 / 3}-\mathrm{k}_{3} \mathrm{t}
$$

Higuchi's square root of time equation (diffusion model)

$$
\mathrm{W}_{\mathrm{t}}=\mathrm{k}_{4} \mathrm{t}
$$

Power law equation (diffusion/relaxation model)

$$
\mathrm{M}_{\mathrm{t}} / \mathrm{M}_{\infty}=\mathrm{k}_{5} \mathrm{t}^{\mathrm{n}}
$$

where $\mathrm{k}$ is the drug release constant; $\mathrm{C}_{\mathrm{t}}$ and $\mathrm{C}_{\mathrm{o}}$ are the concentrations of drug at the initial time and testing time; $W_{t}$ and $W_{o}$ are the weights of the drug at the initial time and testing time; $M_{t} / M_{\infty}$ is the fractional drug release into the dissolution medium; and $\mathrm{n}$ is the diffusional constant that characterizes the drug release transport mechanism. When $\mathrm{n} \leq 0.5$, the drug diffusion from the polymer matrix corresponds to a Fickian diffusion or a quasi-Fickian diffusion mechanism. When $0.5<\mathrm{n}<1$, an anomalous, non-Fickian drug diffusion occurs. When $\mathrm{n}=1$, a non-Fickian, case of II (relaxational) transport or zero-order release kinetics could be observed, and when $\mathrm{n}>1$, super case II transport was observed.

To find the kinetic models for the LS release process from the ACL nanoparticles, the drug release data obtained from section 2.4 were calculated according to the 5 above kinetic equations.

Acute and subchronic toxicity of the alginate/chitosan/lovastatin nanoparticles. Adult healthy Swiss mice were housed in individual cages with a $12 \mathrm{hr}$ light/dark cycle and fed food and water ad 


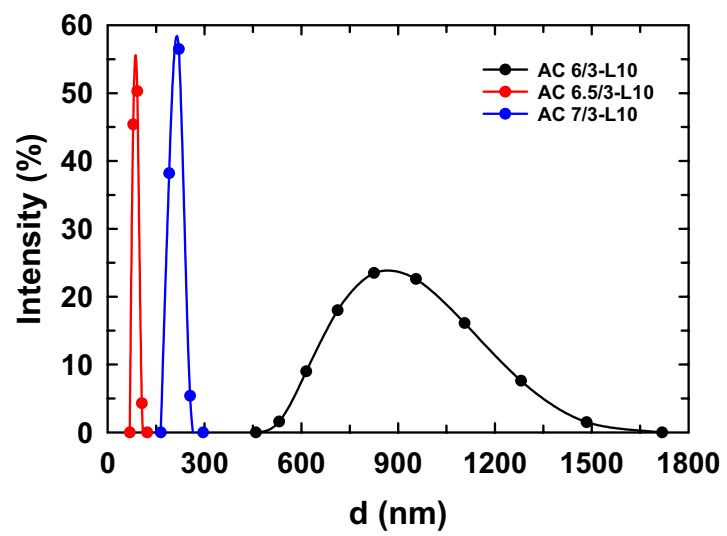

Figure 1. Size distribution diagram of the ACL nanoparticles prepared with different AG/CS ratios.

libitum. Animals were fasted overnight prior to drug injection. The mice were treated in strict compliance with The Animal Center Guidelines for the Care and Use of Laboratory Animals at the Vietnam Military Medical University, consistent with the EU Directive 2010/63/EU. This study was approved by the Committee for Animal Experiments and Ethics (Institutional Animal Care and Use Committee, IACUC) at the Vietnam Military Medical University.

Toxicity evaluation. The acute toxicity in the present study was conducted as per the top-down procedure of the Organization for Economic Cooperation and Development (OECD) guideline with minor modifications ${ }^{25}$.

(i) Limit test

Initially, the ACL nanoparticles were injected into two animals at a single dose of $2000 \mathrm{mg} / \mathrm{kg}$ by oral gavage. Animals were observed once during the first 3-4 hr after the injection and then periodically during the first $72 \mathrm{hr}$. As the two animals were not dead, the drug was administered to two additional animals at a single dose of $5000 \mathrm{mg} / \mathrm{kg}$.

(ii) Main test

Forty adult Swiss mice were randomly divided into 4 groups with 10 animals per group. The animals in each group were injected with a single dose of $500 \mathrm{mg} / \mathrm{kg}, 1000 \mathrm{mg} / \mathrm{kg}, 2000 \mathrm{mg} / \mathrm{kg}$ or $5000 \mathrm{mg} / \mathrm{kg}$. All the animals were observed daily for any abnormal behavior and mortality for $72 \mathrm{hr}$. Thereafter, histological changes in the animal livers and kidneys were examined.

Subchronic toxicity. Repeated-dose oral subchronic toxicity of the ACL nanoparticles was carried out according to OECD guideline $407^{26}$. Animals were randomly divided into 3 groups with 10 animals per group. Group 01 (control): rats were treated with saline; groups 02 and 03: animals were injected with ACL nanoparticles at doses of $100 \mathrm{mg} / \mathrm{kg}$ and $300 \mathrm{mg} / \mathrm{kg}$ (containing $10 \mathrm{mg} / \mathrm{kg}$ and $30 \mathrm{mg} / \mathrm{kg}$ lovastatin), respectively. Animals were administered saline or lovastatin at a dosage of $0.1 \mathrm{ml}$ per $10 \mathrm{~g}$ body weight daily by gavage. After the injection, pharmacotoxic signs and mortality of the animals were observed at $10 \mathrm{~min}, 30 \mathrm{~min}, 60 \mathrm{~min}$, and $4 \mathrm{hr}$ during the first day and daily thereafter for 28 days. The body weights of all animals were recorded weekly before and after dosing. On the $28^{\text {th }}$ day, blood samples were collected from all animals via abdominal aorta puncture for biochemical and hematological analyses. Hematological parameters, including the number of white blood cells (WBCs), number of blood cells (RBCs), hemoglobin (g/dL), hematocrit (\%), MCV (fl), $\mathrm{MCH}(\mathrm{pg}), \mathrm{MCHC}(\%)$, and platelet $\left(10^{3} / \mu \mathrm{L}\right)$, were determined using a Sysmex XN-1000 analyzer (Japan). Biochemical parameters including alanine aminotransferase (ALT), aspartate aminotransferase (AST), creatinine, and urea were analyzed using a fully automated biochemical analyzer (AU 640- Olympus, Japan). On the $29^{\text {th }}$ day, all animals were injected with ketamine at a dose of $30 \mathrm{mg} / \mathrm{kg}$, and their kidneys and livers were excised, weighed, and examined macroscopically. Thereafter, the livers and kidneys were preserved in $10 \%$ buffered formalin for histopathological study.

Data analysis. The body weights, biochemical and hematological indexes were analyzed by repeated two-way ANOVAs following Tukey's test for multiple comparisons. Significant differences were defined at $p<0.01$. All data are expressed as the mean \pm SEM.

\section{Results and Discussion}

The size distribution of the ACL nanoparticles. To investigate the influence of the AG/CS ratio on the size distribution of ACL nanoparticles, the ACL samples were prepared with different AG/CS ratios by ionic gelation, as listed in Table 1. Figure 1 shows the size distribution diagrams of the AC6/3-L10, AC6.5/3-L10, and AC7/3-L10 samples. The particle sizes of all the samples ranged from $68 \mathrm{~nm}$ to $1718 \mathrm{~nm}$. Among the prepared samples, the sample composed of an AG/CS ratio of 6.5/3 had the smallest particles with an average diameter of approximately $86.2 \pm 3.7 \mathrm{~nm}$ (see Table 1 ). In our opinion, the different size distribution of the tested samples might be caused by the diverse interactions between the solvent and drug, the drug and drug, the solvent and polymer, the polymer and polymer, the solvent and solvent, the drug and polymer, and so on. In general, smaller 


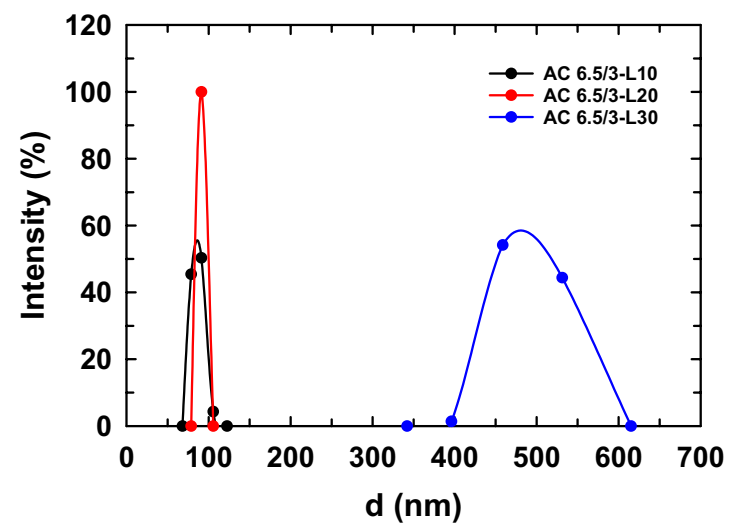

Figure 2. Size distribution diagram of the ACL nanoparticles prepared with different LS contents.

particles are better for dissolution of drugs into solution. Therefore, a suitable AG/CS ratio for the preparation of the ACL nanoparticles is 6.5/3.

The ACL nanoparticles were prepared with the LS content in the range of 10 to $30 \mathrm{wt} . \%$ in comparison with the total weight of AG and CS to investigate the effect of LS content on the size of ACL the nanoparticles (Fig. 2). It was clearly observed that the size of the ACL nanoparticles with LS contents of $10 \mathrm{wt} . \%$ and 20 wt. $\%$ were much smaller than that of the ACL nanoparticles containing $30 \mathrm{wt}$ \% LS (Table 1). This means that using a low content of LS can form ACL nanoparticles with a smaller particle size. This can be explained as follows: at a small concentration of LS, the interactions between the drug and polymer are stronger than the interactions between the drug and drug. Therefore, polymers can absorb a large amount of drug and the drug can be distributed regularly in the ACL nanoparticles, resulting in ACL nanoparticles having a tighter structure and smaller size. In contrast, when using a high concentration of LS, the drug-drug interactions predominate and are stronger than the drug-polymer interactions. Thus, LS can agglomerate in the structure of the ACL nanoparticles and cannot be absorbed completely into the polymers, causing the larger ACL nanoparticle size and LS remaining in solution. As mentioned in other reports, the average size of CS/AG particles for loading drugs is from nanosized to microsized depending on the ratio of CS/AG and the nature of the drug ${ }^{11,14,16-18}$. For example, chitosan/ alginate nanoparticles carrying curcumin diethyl disuccinate (CDD) have an average particle size from 440 to $695 \mathrm{~nm}^{11}$, and alginate-chitosan-pluronic F127 nanoparticles loading curcumin have a particle size of approximately $100 \pm 20 \mathrm{~nm}^{18}$.

Morphology of the ACL nanoparticles. The FE-SEM images of the LS and ACL nanoparticles with different contents of LS are shown in Fig. 3. It is clear that LS is bar-shaped with an irregular size from 150-500 $\mu \mathrm{m}$ (Fig. 3A). The AC6.5/3-L20 and AC6.5/3-L30 nanoparticles have a tendency to agglomerate together from 100$200 \mathrm{~nm}$ sized particles to form larger particles on the micro scale (Fig. 3C,D). Interestingly, the AC6.5/3-L10 nanoparticles are spherical, separate and uniformly sized, at only $50-80 \mathrm{~nm}$ (Fig. 3B). This result is in agreement with the size distribution results mentioned above. Predictably, at $10 \mathrm{wt}$.\% of LS, the LS can interact stronger with polymers and distribute better in the CS and AG. This contributes to the improvement of LS dissolution in buffer solutions.

FTIR spectra of the ACL nanoparticles. Figure 4 presents the FTIR spectra of the ACL nanoparticles prepared with different LS contents. It is clearly visible that there is a slight shift of some characteristic peaks in the spectrum of ACL nanoparticles when compared with the FTIR spectra of LS, CS, and AG, as reported in our previous paper ${ }^{21}$. The stretching vibrations of the $\mathrm{C}=\mathrm{O}$ groups of AC6.5/3-L10, AC6.5/3-L20, and AC6.5/3-L30 nanoparticles are assigned to $1608.27 \mathrm{~cm}^{-1}, 1616.23 \mathrm{~cm}^{-1}$ and $1623.41 \mathrm{~cm}^{-1}$, respectively. This can be described by the difference in the wavenumber of the $\mathrm{C}=\mathrm{O}$ group in the FTIR spectrum of the ACL nanoparticles in comparison with those of CS, AG and LS. In particular, the peaks corresponding to the $\mathrm{NH}_{2}, \mathrm{C}-\mathrm{O}$, and $\mathrm{OH}$ groups in the FTIR spectrum of the ACL nanoparticles are also shifted significantly $\left(3-105 \mathrm{~cm}^{-1}\right)$ in comparison with similar peaks in the FTIR spectra of AG, CS and LS. These changes can be caused by interactions between the $\mathrm{C}=\mathrm{O}, \mathrm{C}-\mathrm{O}$, and $\mathrm{OH}$ groups of $\mathrm{LS}$ with the $\mathrm{C}-\mathrm{O}, \mathrm{NH}$, and $\mathrm{OH}$ groups of $\mathrm{CS}$ and the $\mathrm{C}=\mathrm{O}, \mathrm{C}-\mathrm{O}$, and $\mathrm{OH}$ groups in AG through dipole-dipole interactions and hydrogen bonds (as assumed in Table 2) 7,27,28. A wide peak at approximately $2200 \mathrm{~cm}^{-1}$ in the FTIR spectrum of the ACL nanoparticles corresponds to the presence of the $-\mathrm{NH}_{3} \mathrm{C}$ group in the polyion complex formed by the electrostatic interaction of dissociated carboxylate groups of sodium alginate with protonated amino groups from chitosan ${ }^{29,30}$. In addition, the change in LS content has less of an effect on the structure of the ACL nanoparticles because the wavenumber of some of the characterized groups shifts slightly, between $1-7 \mathrm{~cm}^{-1}$.

Thermal behavior of the ACL nanoparticles. Figure 5 and Table 3 display the DSC diagrams and DSC data of LS, CS, AG and the ACL nanoparticles with different LS concentrations. The melting temperatures of LS, CS and AG were $174.6^{\circ} \mathrm{C}, 106.8^{\circ} \mathrm{C}$ and $119.7^{\circ} \mathrm{C}$, respectively, while the melting temperature of the ACL nanoparticles was $107.2^{\circ} \mathrm{C}-113.4^{\circ} \mathrm{C}$, depending on the LS content and the AG/CS ratio (Table 3 and Fig. 5). 

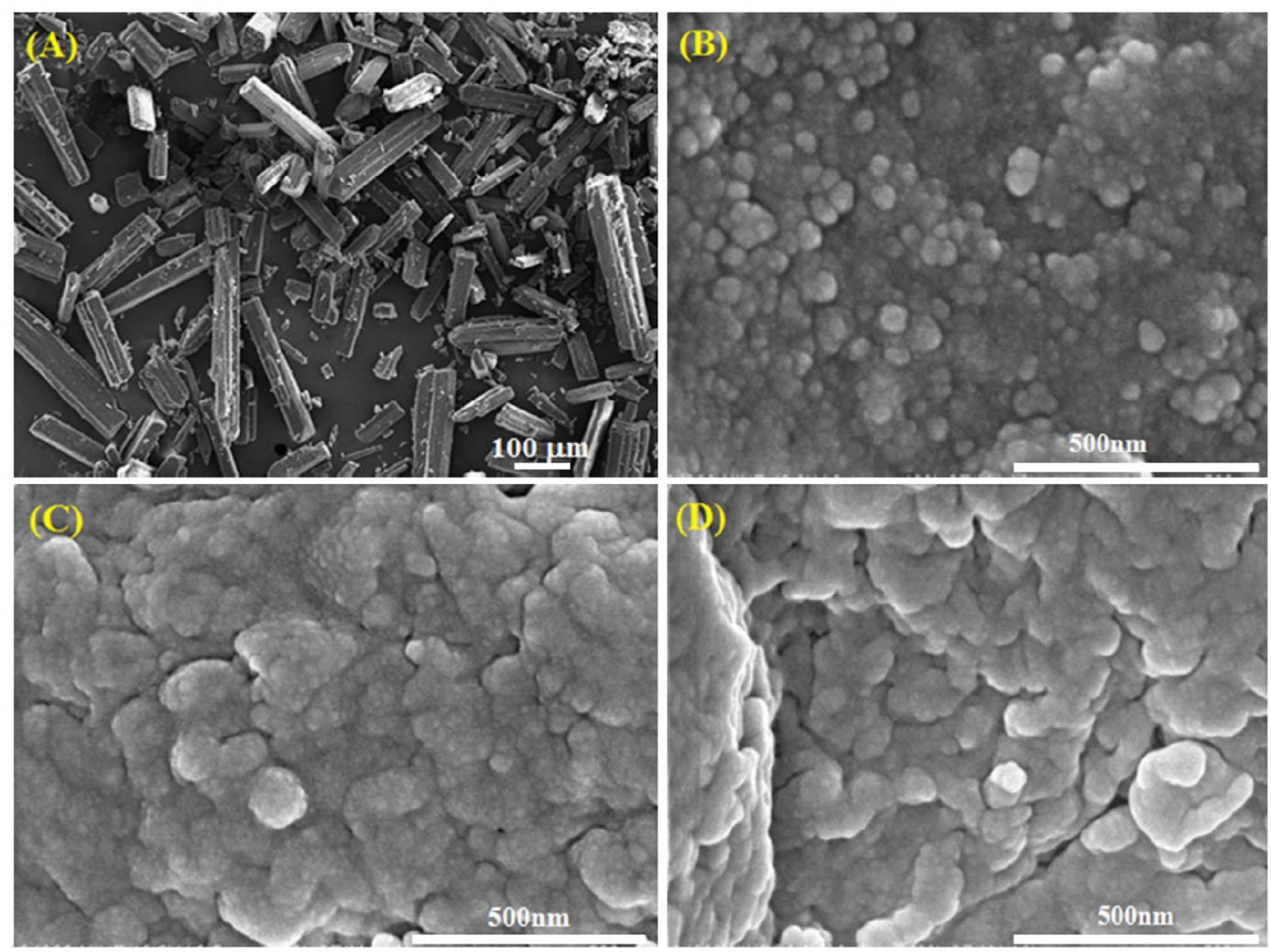

Figure 3. SEM images of the (A) lovastatin; (B) AC6.5/3-L10; (C) AC6.5/3-L20; and (D) AC6.5/3-L30 samples.

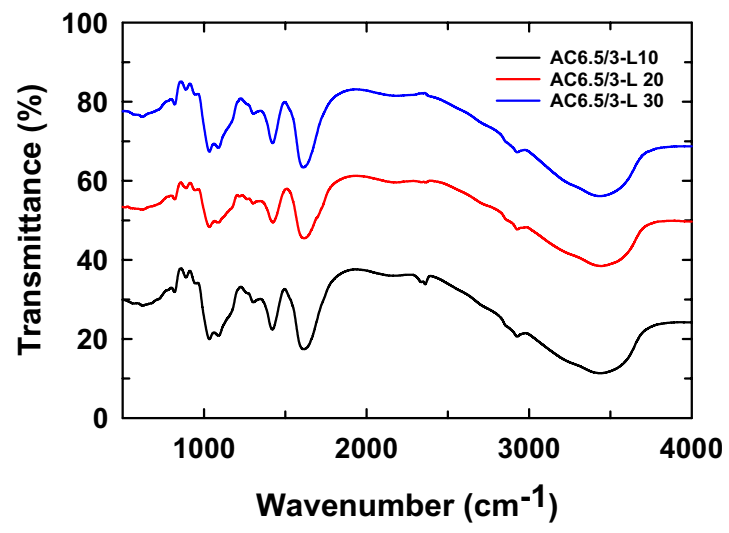

Figure 4. FTIR spectra of the ACL nanoparticles prepared with different LS contents.

Noticeably, the melting temperature of the ACL nanoparticles was higher than that of CS and lower than that of AG. This result confirms that CS and AG are partly compatible through some physical interactions, as mentioned in Table 2. The interaction and compatibility between AG and CS contribute to the formation of a stable structure of ACL nanoparticles, and these nanoparticles could better control drug release. From the data listed in Table 3 and Fig. 5b, the nanoparticles prepared at an AG/CS ratio of 6.5/3 have the highest melting temperature, corresponding to AG and CS in AC6.5/3-L10 nanoparticles. These nanoparticles could be more compatible than the AC6/3-L10 and AC7/3-L10 nanoparticles. In addition, the LS content also affects the interaction and compatibility of AG and CS due to the interactions between the drug and polymer or the drug and drug in the nanoparticle system. Table 3 and Fig. $5 \mathrm{c}$ show the differences in the melting temperatures and melting enthalpies of the ACL nanoparticles with different LS contents. These results can be explained by the weak interaction between LS and CS and AG at the large LS content, leading to an ACL nanoparticle structure that is less tight and melts more easily. As a result, the AC6.5/3-L20 and AC6.5/3-L30 nanoparticles have melting temperatures and melting enthalpies lower than that of the AC6.5/3-L10 nanoparticles. 


\begin{tabular}{|c|c|}
\hline Materials & Type of hydrogen bonding \\
\hline LS & $\mathrm{LS}-\mathrm{C}=\mathrm{O} \ldots \mathrm{H}-\mathrm{O}-\mathrm{LS}$ \\
\hline \multirow{2}{*}{ LS and AG } & LS-O-H...O=C-AG \\
\hline & $\mathrm{LS}-\mathrm{C}=\mathrm{O} \ldots \mathrm{H}-\mathrm{O}-\mathrm{AG}$ \\
\hline \multirow{4}{*}{ LS and CS } & $\mathrm{LS}-\mathrm{C}=\mathrm{O} \ldots \mathrm{H}-\mathrm{O}-\mathrm{CS}$ \\
\hline & $\mathrm{LS}-\mathrm{C}=\mathrm{O} \ldots \mathrm{H}-\mathrm{N}-\mathrm{CS}$ \\
\hline & LS-O-H...O(H)-CS \\
\hline & LS-O-H...N(H)-CS \\
\hline \multirow{2}{*}{ CS and CS } & CS-N-H...O(H)-CS \\
\hline & CS-O-H...N(H)-CS \\
\hline $\mathrm{AG}$ and $\mathrm{AG}$ & AG-O-H...O=C-AG \\
\hline \multirow{4}{*}{$\mathrm{CS}$ and $\mathrm{AG}$} & $\mathrm{AG}-\mathrm{C}=\mathrm{O} \ldots \mathrm{H}-\mathrm{O}-\mathrm{CS}$ \\
\hline & $\mathrm{AG}-\mathrm{C}=\mathrm{O} \ldots \mathrm{H}-\mathrm{N}-\mathrm{CS}$ \\
\hline & AG-O-H...O(H)-CS \\
\hline & AG-O-H...N(H)-CS \\
\hline
\end{tabular}

Table 2. Predicted hydrogen bonding interactions of AG, CS and LS.

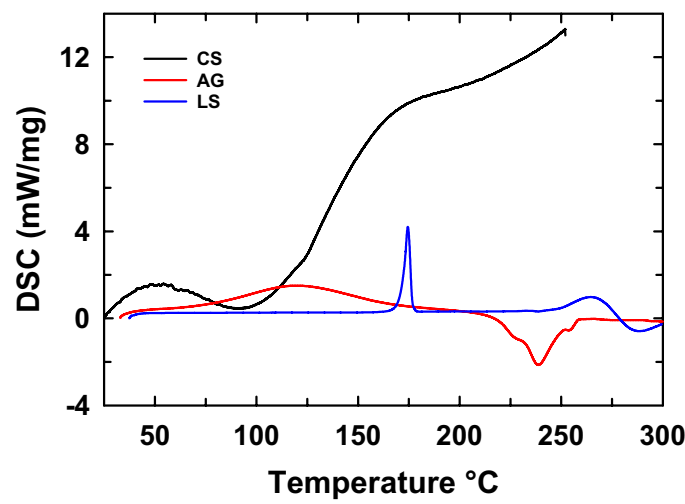

(a)

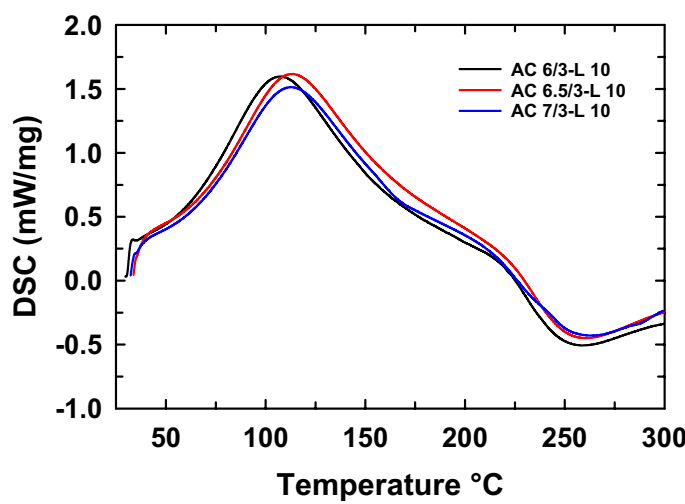

(b)

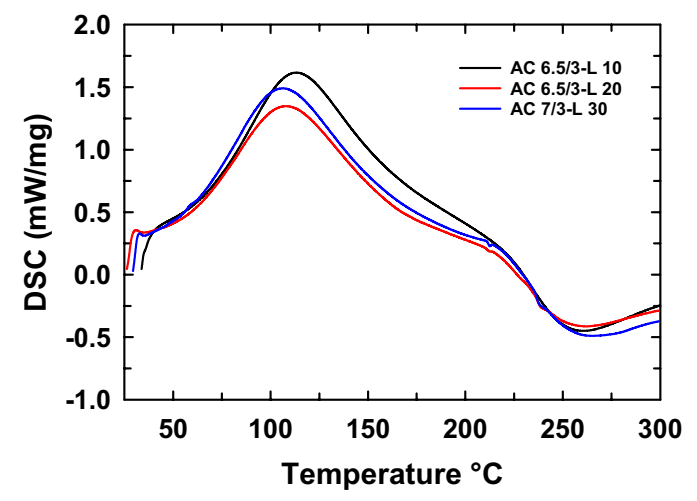

(c)

Figure 5. DSC diagrams of the CS, AG, LS (a), ACL nanoparticles with different AG/CS ratios (b) and ACL nanoparticles with different LS contents (c).

Drug release study. Effect of the AG/CS ratio on drug release content from the ACL nanoparticles. The results of the effects of the AG/CS ratio on the LS release content from the ACL nanoparticles tested in a pH 7.4 solution are shown in Fig. 6. Interestingly, LS is quickly released from the nanoparticles in the initial $10 \mathrm{hr}$ and then the release is slower or/and controlled. The AG/CS ratio remarkably influences the drug release content from ACL nanoparticles. For instance, more than $50 \mathrm{wt} . \%$ of the drug is released from the AC6.5/3-L10 nanoparticles after testing for $2 \mathrm{hr}$. This result is similar to AG/CS nanoparticles loaded with other drugs, such as 5-fluorouracil (5-FU), tegafur, and verapamil ${ }^{9,19}$. After testing for $30 \mathrm{hr}$, the LS released from the ACL nanoparticles at $\mathrm{pH} 7.4$ reached $93.38 \%, 69.45 \%$ and $44.18 \%$, corresponding to the AC6.5/3-L10, AC6/3-L10, and AC7/3-L10 samples, respectively. The reason LS releases from the AC6.5/3-L10 sample more quickly than from the AC6/3-L10, and 


\begin{tabular}{|l|l|l|}
\hline Sample & $\mathbf{T}_{\mathbf{m}}\left({ }^{\circ} \mathbf{C}\right)$ & $\Delta \mathbf{H}_{\mathbf{m}}(\mathbf{J} / \mathbf{g})$ \\
\hline AG & 119.7 & 358.6 \\
\hline LS & 174.6 & 90.3 \\
\hline CS & 106.8 & 130.6 \\
\hline AC6/3-L10 & 107.6 & 590.4 \\
\hline AC7/3-L10 & 112.6 & 501.3 \\
\hline AC6.5/3-L10 & 113.4 & 545.2 \\
\hline AC6.5/3-L20 & 107.5 & 467.4 \\
\hline AC6.5/3-L30 & 107.2 & 541.3 \\
\hline
\end{tabular}

Table 3. Melting temperature $\left(\mathrm{T}_{\mathrm{m}}\right)$ and melting enthalpy $\left(\Delta \mathrm{H}_{\mathrm{m}}\right)$ of AG, CS, LS and the ACL nanoparticles.

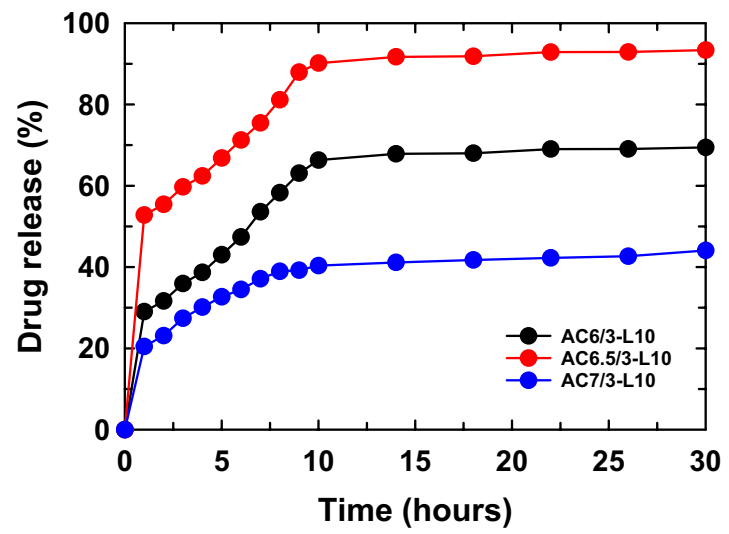

Figure 6. LS released from the ACL nanoparticles prepared with different AG/CS ratios in solution at pH 7.4.

AC7/3-L10 nanoparticles might be due to the smaller particle size of the AC6.5/3-L10 sample. Due to the smaller particle size, the nanoparticles can dissolve and diffuse into the buffer solution more easily, releasing LS from the nanoparticles faster.

Investigation of the effect of solution $p H$ on drug release from the ACL nanoparticles. Figure 7 presents the LS content released from the AC6.5/3-L10 nanoparticles in solutions of different $\mathrm{pH}$ values $(\mathrm{pH} 2.0,4.5,6.5$, and 7.4). The LS content released from AC6.5/3-L10 nanoparticles in different $\mathrm{pH}$ solutions, such as 2.0, 4.5, 6.5, and 7.4, displayed that the solution $\mathrm{pH}$ strongly affected the drug release content. After $30 \mathrm{hr}$ of testing, the LS content released from the AC6.5/3-L10 nanoparticles at $\mathrm{pH} 7.4,6.5,4.5$ and 2.0 corresponded to $93.38 \%, 90.44 \%$, $84.15 \%$ and $83.04 \%$, respectively. It can be concluded that the LS release content from AC6.5/3-L10 nanoparticles in different $\mathrm{pH}$ solutions is on the order of $\mathrm{pH} 7.4>\mathrm{pH} 6.5>\mathrm{pH} 4.5>\mathrm{pH}$ 2.0. The results obtained from the AC6.5/3-L20 and AC6.5/3-L30 nanoparticles were similar to the release values of LS from the AC6.5/3-L10 nanoparticles. The LS released from these samples also followed the order $\mathrm{pH} 7.4>\mathrm{pH} 6.5>\mathrm{pH} 4.5>\mathrm{pH} 2$ (Fig. 7b,c). The faster drug release from the ACL nanoparticles in the neutral environment compared with that in an acidic environment could be caused by the repulsion between $\mathrm{H}^{+}$ions (in acidic $\mathrm{pH}$ ) and cations on the surface of the CS, inhibiting the hydrolysis of the polymer ${ }^{4,20,31}$. These results indicate that the ACL nanoparticles are better suited for the basic environment of the large intestine, colon and rectal mucosa than an acidic environment.

Effect of the initial LS content on drug release content from the ACL nanoparticles. Figures 8-11 show the LS content released from the control sample and ACL nanoparticles prepared using different LS concentrations in different buffer solutions. It was found that the ACL nanoparticles containing a high LS content during the initial phase of the test period released less LS when compared with the ACL nanoparticles having a low LS concentration, where the release of LS from the ACL particles was higher. This drug release pattern occurred at all tested $\mathrm{pH}$ values, including 7.5, 6.5, 4.5 and 2. The particle size of the ACL nanoparticles increased as the LS concentration increased; therefore, smaller nanoparticles have a faster drug release ability, as mentioned above. The drug release in the high LS-loaded ACL nanoparticles was slower due to the existence of more free void space between larger-sized nanoparticles and LS; therefore, drug molecule transport and diffusion of the drugs into solution became more difficult. Comparing the LS control sample and the AC6.5/3-L10 nanoparticles in solutions of different $\mathrm{pH}$, it is clear that at the initial stage, the LS released from the AC6.5/3-L10 nanoparticles is remarkably faster than the release from the LS sample without nanoparticle loading. It is interesting to note that, at $\mathrm{pH} 7.4$, the drug released from the AC6.5/3-L10 nanoparticles after $1 \mathrm{hr}$ of testing was 52.8\%, which was much higher than the LS control sample, where the drug release was only $17.1 \%$ (Fig. 8). The same drug release pattern was observed at all other tested $\mathrm{pH}$ values of $6.5,4.5$ and 2 over the same one hour testing duration. This confirms that LS loaded in the AG/CS nanoparticles can dissolve and diffuse more easily into the buffer solution 

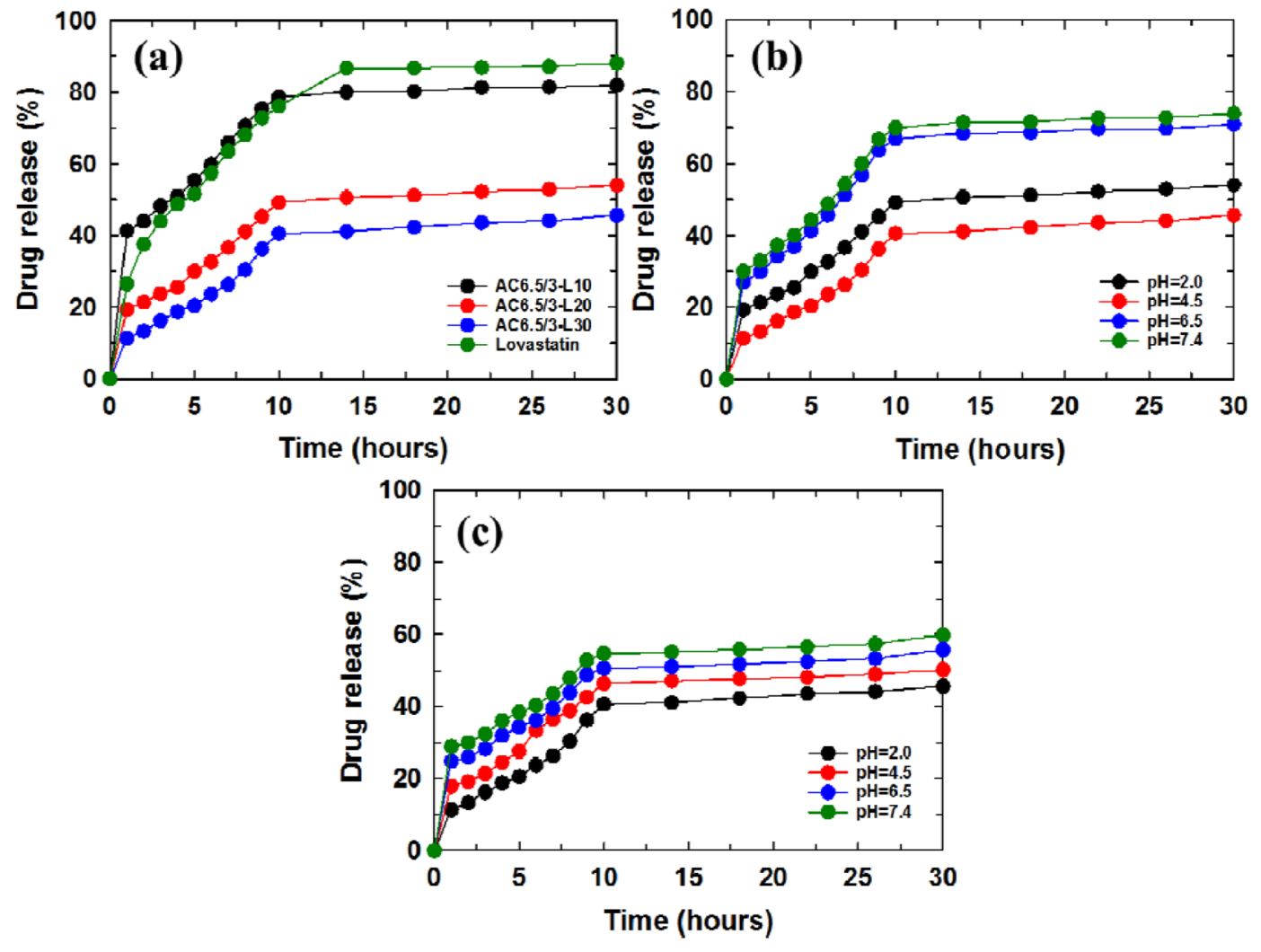

Figure 7. LS released from (a) AC6.5/3-L10, (b) AC6.5/3-L20 and (c) AC6.5/3-L30 nanoparticles in different $\mathrm{pH}$ solutions.

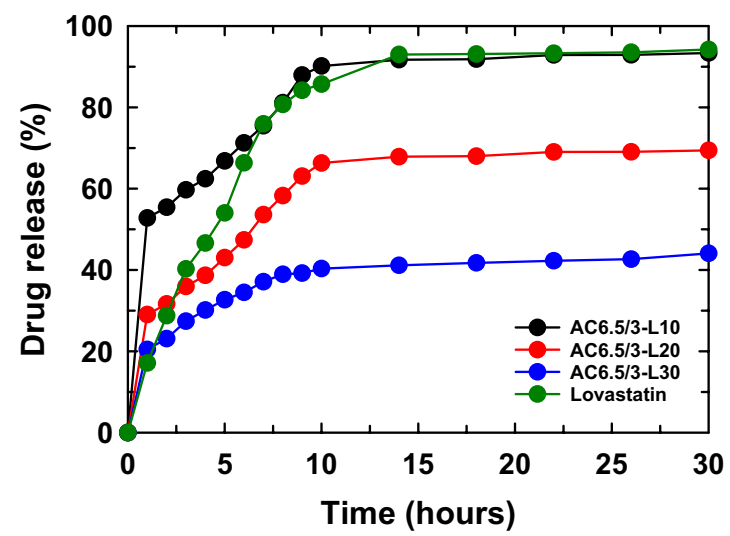

Figure 8. LS released from the ACL nanoparticles in solution at $\mathrm{pH} 7.4$.

than the drug that was not loaded into the nanoparticle. The AG/CS blend can be used as a suitable carrier for LS to improve its dissolution.

Drug release kinetic study. The kinetic equation and regression coefficients $\left(\mathrm{R}^{2}\right)$ of the LS release process from the AC6.5/3-L10 nanoparticles in solution at $\mathrm{pH} 7.4$ are displayed in Fig. 12. The regression coefficient value from the Hixson-Crowell model, is the most appropriate for studying the LS release kinetics from AC6.5/3-L10 nanoparticles in solution $\mathrm{pH} 7.4$ at the first stage $\left(\mathrm{R}^{2}=0.996\right)$, while the Korsmeyer-Peppas model (diffusion/ relaxation model) is the most suitable for studying the LS release kinetics from the AC6.5/3-L10 nanoparticles at $\mathrm{pH} 7.4$ at the controlled stage $\left(\mathrm{R}^{2}=0.947\right)$. This result means that in the fast release stage for the first $9 \mathrm{hr}$, the mechanism for the release of LS from the AC6.5/3-L10 nanoparticles into the $\mathrm{pH} 7.4$ solution resulted from the system having a change in the surface area and particle size. This suggested that the dissolution of the drug occurred together with the dissolution of alginate in the AC6.5/3-L10 nanoparticles, leading to a decrease in the diameter of the nanoparticles. For the controlled stage or slow stage from 10 to $30 \mathrm{hr}$, the suitability of the 


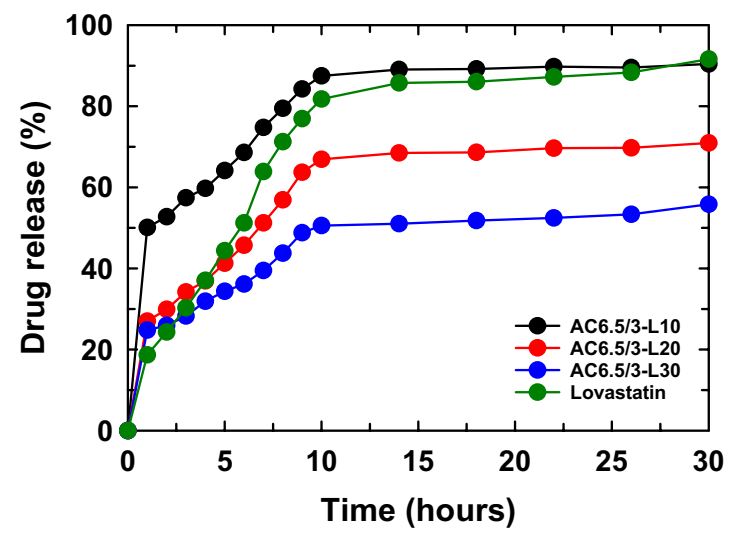

Figure 9. LS released from the ACL nanoparticles at $\mathrm{pH} 6.5$.

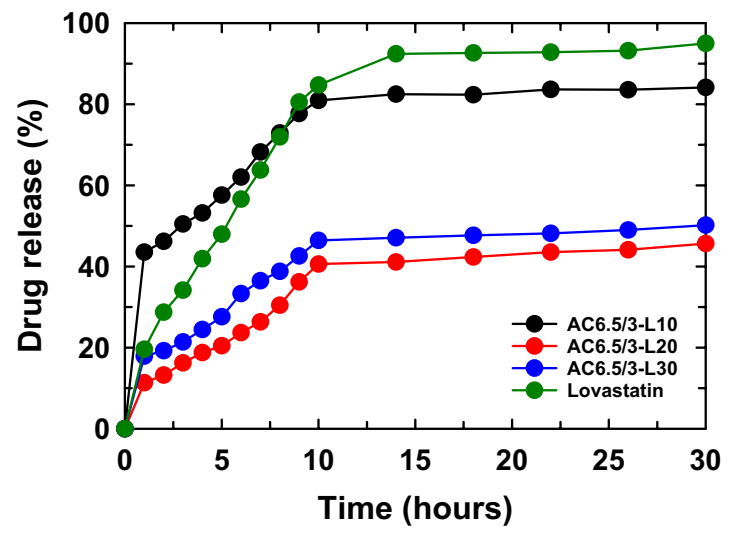

Figure 10. LS released from the ACL nanoparticles at $\mathrm{pH} 4.5$.

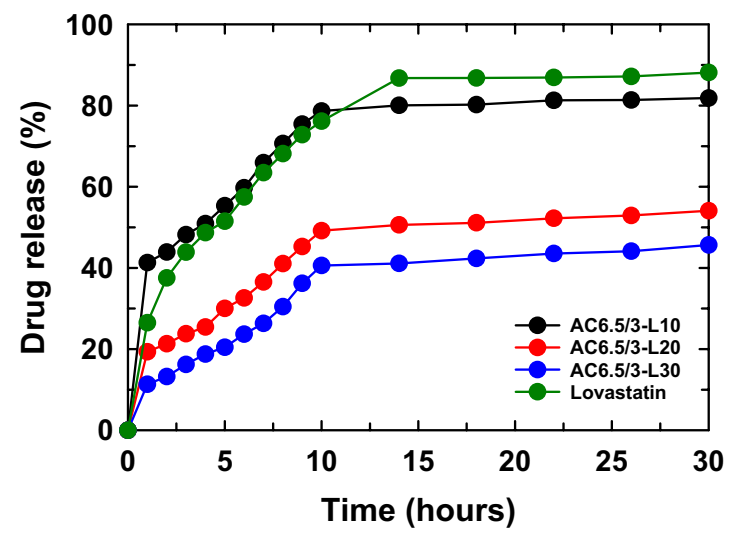

Figure 11. LS released from the ACL nanoparticles at pH 2.

Korsmeyer-Peppas model $\left(\mathrm{R}^{2}=0.947\right)$ for LS release from the AC6.5/3-L10 nanoparticles into $\mathrm{pH} 7.4$ solution proves that the drug mechanism was a combination of many processes, including the swelling and dissolution of the polymers, the diffusion and dissolution of the drug, and so on. These results comply with the LS release from the other polymers in other literature reports ${ }^{1,2,20}$.

The regression coefficients of the LS release process for the AC6.5/3-L10 nanoparticles in solutions of different $\mathrm{pH}(6.5,4.5$ and 2.0) according to the different kinetic models were also determined and are reported in Table 4. From the data in Table 4, it is clear that the fast drug release and slow drug release processes comply with different kinetic models in different $\mathrm{pH}$ solutions. For the initial stage, LS released from the AC6.5/3-L10 nanoparticles follows the Korsmeyer-Peppas model with the highest regression coefficients corresponding to $\mathrm{pH}$ values of 6.5 , 4.5 and 2.0 , which were $0.997,0.989$, and 0.998 , respectively. Therefore, it can be concluded that the LS release 

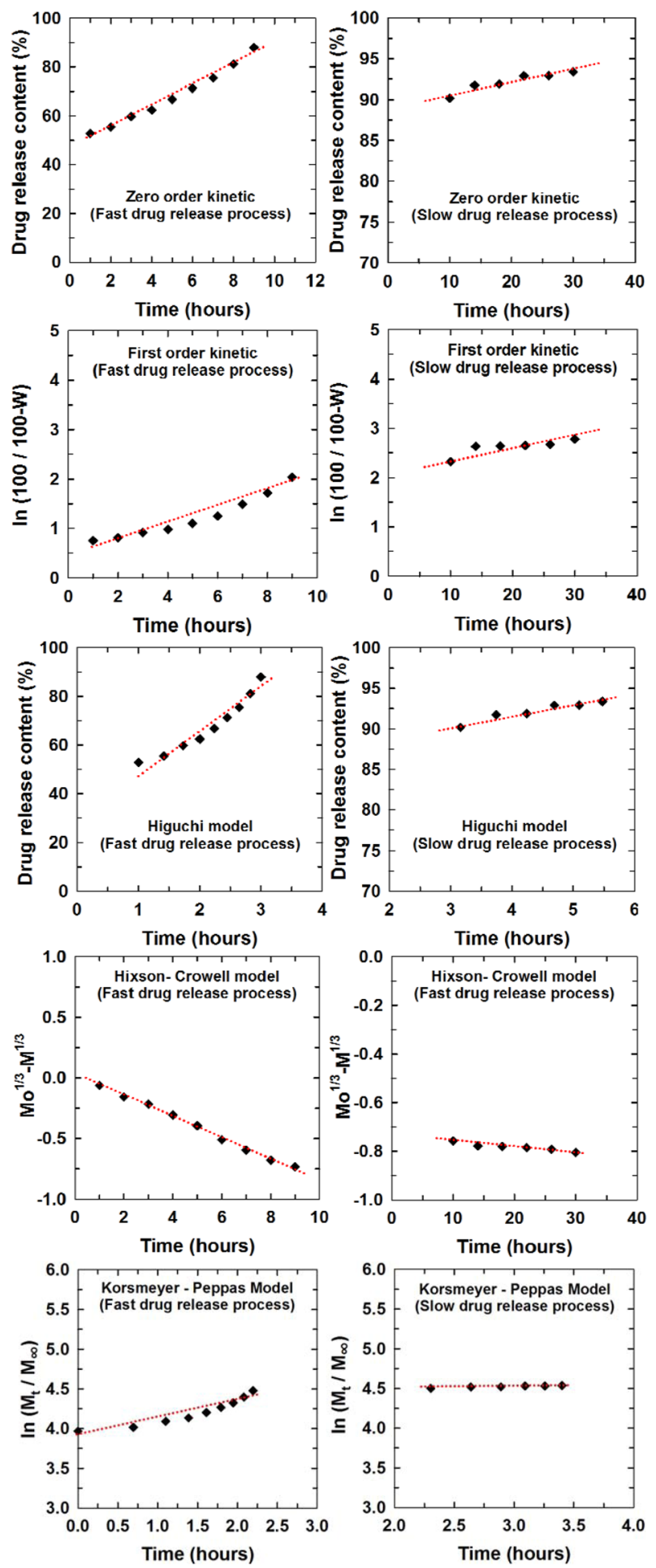

Figure 12. Kinetic equations fit to different models (Eqs. 1-5 in section 2.5), reflecting LS release from the AC6.5/3-L10 nanoparticles in $\mathrm{pH} 7.4$ solution.

from AC6.5/3-L10 nanoparticles at the initial stage is complex. In the subsequent stage, LS release from the AC6.5/3-L10 nanoparticles is simpler, except for the solution at $\mathrm{pH}$ 2.0. For instance, in the solutions at $\mathrm{pH} 6.5$ and 4.5, the LS release process from the AC6.5/3-L10 nanoparticles complied with the zero order kinetic model and first order kinetic model. In the case of the solution at $\mathrm{pH} 2.0$, the dissolution of CS in the acidic environment caused a remarkable effect on the LS release process, leading to a complex drug release mechanism.

Acute toxicity. According to the Organization for Economic Cooperation and Development - OECD guideline No. $423^{25}$, a compound/material that possesses an $\mathrm{LD}_{50}$ greater than $5000 \mathrm{mg} / \mathrm{kg}$ b.w. could be assigned as a 


\begin{tabular}{|l|l|l|l|l|l|}
\hline \multirow{2}{*}{ Solution } & \multicolumn{5}{|l}{ Drug release process (fast) } \\
\cline { 2 - 6 } & ZO & FO & HG & HCW & KMP \\
\hline pH 7.4 & 0.985 & 0.932 & 0.935 & 0.996 & 0.888 \\
\hline pH 6.5 & 0.957 & 0.987 & 0.938 & 0.965 & 0.997 \\
\hline pH 4.5 & 0.967 & 0.989 & 0.914 & 0.899 & 0.989 \\
\hline pH 2.0 & 0.983 & 0.966 & 0.927 & 0.919 & 0.998 \\
\hline \multirow{2}{*}{ Solution } & Drug release process (slow) \\
\cline { 2 - 6 } & ZO & FO & HG & HCW & KMP \\
\hline pH 7.4 & 0.889 & 0.707 & 0.923 & 0.925 & 0.947 \\
\hline pH 6.5 & 0.990 & 0.921 & 0.924 & 0.932 & 0.983 \\
\hline pH 4.5 & 0.954 & 0.971 & 0.967 & 0.931 & 0.956 \\
\hline pH 2.0 & 0.965 & 0.968 & 0.970 & 0.905 & 0.979 \\
\hline
\end{tabular}

Table 4. Regression coefficients obtained from the kinetic equations reflecting LS release from AC6.5/3-L10 nanoparticles in solutions of different $\mathrm{pH}$ values (ZO: zero order kinetic model; FO: first order kinetic model; HG: Higuchi model; HCW: Hixson-Crowell model; KMP: Korsmeyer- Peppas model).

\begin{tabular}{|l|l|l|l|}
\hline \multirow{2}{*}{ Week } & \multirow{2}{*}{ Control $(\mathrm{g}, \pm$ SEM) } & \multicolumn{3}{|l|}{ ACL nanoparticle groups $(\mathrm{g}, \pm$ SEM) } \\
\cline { 3 - 4 } & Dose of $\mathbf{1 0 0} \mathbf{~} \mathbf{g} / \mathbf{k g}$ & Dose of $\mathbf{3 0 0} \mathbf{~ m g} / \mathbf{k g}$ \\
\hline 0 & $185.16 \pm 13.68$ & $176.00 \pm 14.20$ & $198.33 \pm 13.78$ \\
\hline 1 & $187.16 \pm 13.78$ & $176.66 \pm 14.30$ & $199.66 \pm 13.77$ \\
\hline 2 & $195.00 \pm 15.66$ & $188.83 \pm 16.26$ & $206.50 \pm 15.89$ \\
\hline 3 & $198.33 \pm 16.53$ & $196.66 \pm 17.12$ & $213.83 \pm 16.65$ \\
\hline 4 & $205.16 \pm 17.73$ & $205.00 \pm 18.32$ & $223.00 \pm 17.74$ \\
\hline
\end{tabular}

Table 5. Mean body weights of the three rat groups (without and with the use of ACL nanoparticles) after the 28 day treatment period.

\begin{tabular}{|l|c|c|c|}
\hline \multirow{2}{*}{ Parameter } & \multirow{2}{*}{ Control $($ mean \pm SEM) } & \multicolumn{2}{|l|}{ ACL nanoparticle groups (mean \pm SEM) } \\
\cline { 3 - 4 } & Dose of $\mathbf{1 0 0} \mathbf{~} \mathbf{g} / \mathbf{k g}$ & Dose of 300 $\mathbf{~ m g} / \mathbf{k g}$ \\
\hline WBC $\left(10^{3} / \mu \mathrm{l}\right)$ & $8.01 \pm 0.863$ & $8.24 \pm 0.916$ & $8.19 \pm 0.866$ \\
\hline RBC $\left(10^{6} / \mu \mathrm{l}\right)$ & $6.66 \pm 0.189$ & $6.83 \pm 0.125$ & $6.19 \pm 0.313$ \\
\hline Hemoglobin $(\mathrm{g} / \mathrm{dL})$ & $11.88 \pm 0.295$ & $12.09 \pm 0.279$ & $10.88 \pm 0.465$ \\
\hline Hematocrit $(\%)$ & $36.48 \pm 0.979$ & $36.68 \pm 1.037$ & $33.08 \pm 1.352$ \\
\hline MCV $(\mathrm{fl})$ & $54.02 \pm 0.885$ & $53.27 \pm 0.886$ & $53.67 \pm 0.692$ \\
\hline MCH $(\mathrm{pg})$ & $17.88 \pm 0.190$ & $17.55 \pm 0.238$ & $17.67 \pm 0.186$ \\
\hline MCHC $(\%)$ & $32.66 \pm 0.276$ & $33.05 \pm 0.304$ & $32.94 \pm 0.249$ \\
\hline Platelets $\left(10^{3} / \mu \mathrm{l}\right)$ & $481.80 \pm 46.490$ & $368.90 \pm 65.180$ & $468.90 \pm 68.120$ \\
\hline
\end{tabular}

Table 6. Hematological parameters of the three rat groups without and with ACL nanoparticles after the 28 day treatment period.

\begin{tabular}{|l|c|l|c|}
\hline \multirow{2}{*}{ Parameter } & \multirow{2}{*}{ Control (mean \pm SEM) } & \multicolumn{2}{|l|}{ ACL nanoparticle groups (mean \pm SEM) } \\
\cline { 3 - 4 } & $153.31 \pm 11.92$ & Dose of $\mathbf{1 0 0} \mathbf{~} \mathbf{g} / \mathbf{k g}$ & Dose of $\mathbf{3 0 0} \mathbf{~ m g} / \mathbf{k g}$ \\
\hline AST (U/L) & $38.22 \pm 3.849$ & $198.03 \pm 46.84$ & $158.10 \pm 19.82$ \\
\hline ALT (U/L) & $65.42 \pm 2.769$ & $71.16 \pm 1.909$ & $45.94 \pm 4.708$ \\
\hline Creatinine (mg/dL) & $4.64 \pm 0.392$ & $4.16 \pm 0.231$ & $60.31 \pm 4.629$ \\
\hline Urea (\%) & & & $4.98 \pm 0.397$ \\
\hline
\end{tabular}

Table 7. Biochemical parameters of the three rat groups with and without the use of ACL nanoparticles after the 28 day treatment period.

Class 5 substance and be considered nontoxic or less toxic. From the results of the limit test and the main acute toxicity studies, all animals from the experimental groups did not appear to have any obvious symptoms of toxicity. After drug administration for $72 \mathrm{hr}$, two animals with a single dose of $2000 \mathrm{mg} / \mathrm{kg}$ and four animals with a single dose of $5000 \mathrm{mg} / \mathrm{kg}$ were not dead. It is clear that the median lethal dose $\left(\mathrm{LD}_{50}\right)$ of the ACL nanoparticles is higher than $5000 \mathrm{mg} / \mathrm{kg}^{25}$. 


\begin{tabular}{|l|c|l|l|}
\hline \multirow{2}{*}{ Organ } & \multirow{2}{*}{ Control group $(\mathrm{g}, \pm$ SEM) } & \multicolumn{3}{|c|}{ ACL nanoparticle groups $(\mathrm{g}, \pm \mathrm{SEM})$} \\
\cline { 3 - 4 } & Dose of $\mathbf{1 0 0} \mathbf{~ m g} / \mathbf{k g}$ & Dose of $\mathbf{3 0 0} \mathbf{~ m g} / \mathbf{k g}$ \\
\hline Liver & $6.43 \pm 0.28$ & $6.32 \pm 0.44$ & $6.53 \pm 0.58$ \\
\hline Kidney & $1.29 \pm 0.099$ & $1.248 \pm 0.058$ & $1.402 \pm 0.116$ \\
\hline Spleen & $0.332 \pm 0.023$ & $0.342 \pm 0.025$ & $0.354 \pm 0.028$ \\
\hline
\end{tabular}

Table 8. Mean weights of the rat organs in the three rat groups without and with ACL nanoparticles after the 28 day treatment period.

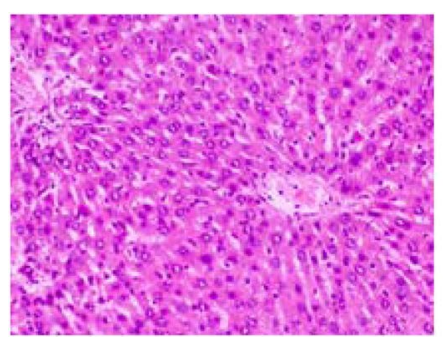

Control

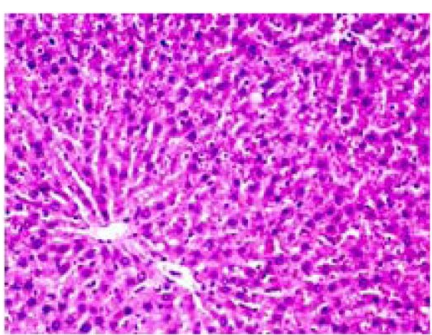

Dose of $100 \mathrm{mg} / \mathrm{kg}$

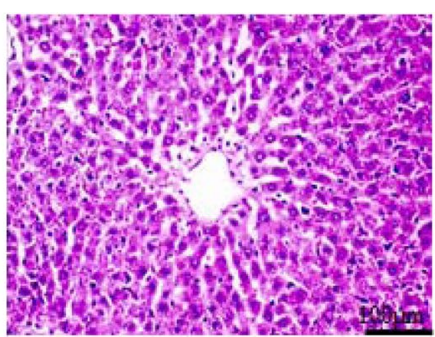

Dose of $300 \mathrm{mg} / \mathrm{kg}$

Figure 13. Histological changes in the livers of rats (without and with ACL nanoparticles) after the 28 day treatment period.

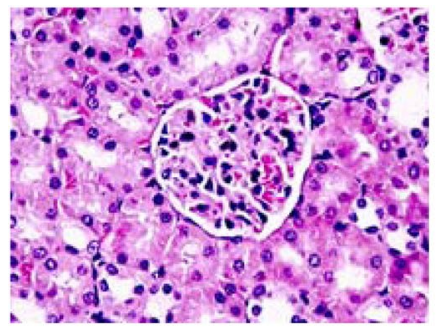

Control

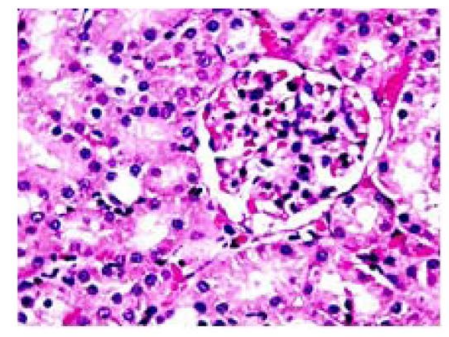

Dose of $100 \mathrm{mg} / \mathrm{kg}$

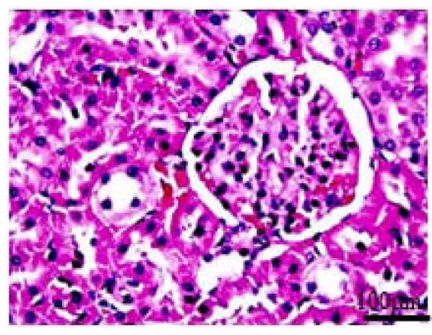

Dose of $300 \mathrm{mg} / \mathrm{kg}$

Figure 14. Histological changes in the kidneys of the three rat groups (without and with the use of ACL nanoparticles) after the 28 day treatment period.

Subchronic toxicity. During a 28 day period of testing, three rat groups were used for the drug loading study (with and without the use of $100 \mathrm{mg} / \mathrm{kg}$ or $300 \mathrm{mg} / \mathrm{kg}$ ACL nanoparticles), and there were no serious abnormal signs or mortality found. Table 5 shows that the body weights of rats in three rat groups increased naturally throughout the treatment period (0-28 days).

Table 6 displays the hematological parameters of the three rat groups without and with ACL nanoparticle treatment after a 28 day treatment period. It is clear that there were no significant differences in the hematological parameters between these rat groups.

Table 7 demonstrates the biochemical parameters of the three rat groups with and without the use of ACL nanoparticles after the 28 day treatment period. There were no significant differences in the biochemical parameters between these rat groups.

After the 28 day treatment period, the organs of all rats in the three experimental groups were excised, weighed, and examined macroscopically. Table 8 shows the weights of some of the important organs from the rats. The results using one-way ANOVA software indicated that there were no significant differences in the liver, kidney, and spleen weights between the three tested rat groups $(\mathrm{p}>0.05)$.

Histological changes in the livers of three tested rat groups with and without ACL nanoparticles after the 28 day treatment period were normal, while fatty degeneration in hepatocytes was observed in both ACL nanoparticle-treated rat groups (Fig. 13). However, the kidney sections of these rat groups after the 28 day treatment period indicated hemorrhage in the glomerulus and interstitial tissue (Fig. 14).

Histopathology of the liver: bright-field image of an H\&E stained section showing the normal hepatic architecture and the components of basic liver lobules with the portal area. Liver cells were arranged in a funicular pattern along with central veins and healthy Kupffer cells. The portal area contained no inflammatory cells. The scale bar is $100 \mu \mathrm{m}$. 
Histopathology of the kidney: Images of H\&E stained sections showing the glomerular and renal vein with edema exudate and a clear Bowman cavity with a normal kidney basement membrane. The vascularity of the cells was normal with relatively healthy tubular epithelial cells. The scale bar is $100 \mu \mathrm{m}$.

From the obtained results of the acute and subchronic toxicities for the three rat groups with and without ACL nanoparticles after the 28 day treatment period, the median lethal dose $\left(\mathrm{LD}_{50}\right)$ of the ACL nanoparticles is greater than $5000 \mathrm{mg} / \mathrm{kg}$. According to the classification reported by Diener et al. (1995), substances with $\mathrm{LD}_{50}$ values of $5000 \mathrm{mg} / \mathrm{kg}$ or above are considered practically nontoxic ${ }^{32}$. Thus, there were no symptoms of serious toxicity and mobility, suggesting that the drug is safe in both the acute and subchronic tests. Furthermore, the histopathological investigations of the livers and kidneys showed that administration of the alginate/chitosan/lovastatin nanoparticles induced no serious changes to the histological images of the livers or kidneys.

In summary, AC nanoparticles carrying $10 \mathrm{wt}$.\% lovastatin were tested to evaluate the acute and subchronic toxicities in three groups of rats. The biochemical and hematological parameters and organ function and structural integrity of the rat groups treated with ACL nanoparticles indicated that there were no significant differences after 28 days- of treatment. The obtained results showed that the nanoparticles might not be harmful. Previous studies have indicated that the $\mathrm{LD}_{50}$ of lovastatin was higher than $1000 \mathrm{mg} / \mathrm{kg}^{33}$. These results are consistent with our previous results from acute toxicity studies. Lovastatin has been used at a dose as low as $10 \mathrm{mg} / \mathrm{kg}$ to lower serum cholesterol in rats ${ }^{34}$. Our ACL nanoparticles might be safe, nontoxic or generally less toxic and also not alter the function and structure of some crucial organs in the experimental animals according to OECD guideline $407^{26}$.

\section{Conclusions}

It has been concluded from this study that a suitable AG/CS ratio for the preparation of ACL nanoparticles by the ionic gelation method is 6.5/3 (wt.\%/wt.\%). The ACL nanoparticles were synthesized successfully in a size range of between $50-100 \mathrm{~nm}$. FTIR spectra showed that LS, CS and AG interact with each other and change the structure and shape of the ACL nanoparticles. The results of the DSC analysis confirm that CS and AG are partly compatible. The LS release from the AC6.5/3-L10 nanoparticles was higher than that from all other investigated samples at different AG/CS ratios, solution $\mathrm{pH}$ values and initial LS contents. The drug release process was divided into two stages: a rapid release in the first $10 \mathrm{hr}$, then it a gradual and stable release. The Korsmeyer-Peppas model with a complex mechanism is most suitable for the LS release process from ACL nanoparticles in the initial stage, and then, in the slow release stage, drug release complies with the Higuchi model, zero order kinetic model, first order kinetic model or Korsmeyer-Peppas model depending on the solution $\mathrm{pH}$. From the obtained results, it can be confirmed that $10 \mathrm{wt} . \%$ LS is appropriate for further application of ACL nanoparticles in treatment. Our in vivo results show that ACL nanoparticles are safe, nontoxic and might be applied to lower serum cholesterol in animal models as well as humans.

Received: 23 May 2019; Accepted: 31 December 2019;

Published online: 22 January 2020

\section{References}

1. Ochoa, L. et al. Novel extended-release formulation of lovastatin by one-step melt granulation: In vitro and in vivo evaluation. Eur. J. Pharm. Biopharm. 77, 306-312 (2011).

2. Sandhya, P., Kodali, G. \& Fatima, A. Formulation and in-vitro characterization of gastro retentive mucoadhesive tablets of Lovastatin. Int. J. Biol. Pharm. Res. 5(1), 71-77 (2014).

3. Anilkumar, J. S. \& Harinath, N. M. Lovastatin loaded chitosan nanoparticles: Preparation, evaluation and in vitro release studies. J. Pharm. Technol. 4(12), 1869-1876 (2011).

4. Tarafder, S., Nansen, K. \& Bose, S. Lovastatin release from polycaprolactone coated $\beta$-tricalcium phosphate: Effects of pH, concentration and drug-polymer interactions. Mater. Sci. Eng. C. 33, 3121-3128 (2013).

5. Bor-Shiunne, L. et al. Controlled-release of tetracycline and lovastatin by poly(d,l-lactide-co-glycolide acid)-chitosan nanoparticles enhances periodontal regeneration in dogs. Int. J. Nanomed. 11, 285-297 (2016).

6. Bernal, S. et al. Preparation of alginate-chitosan fibers with potential biomedical applications. Carbohyd Polym. 134, 598-608 (2015).

7. Lacerda, L., Luis Parize, A., Fávere, V., Laranjeira, M. C. M. \& Stulzer, H. K. Development and evaluation of pH-sensitive sodium alginate/chitosan microparticles containing the antituberculosis drug rifampicin. Mater. Sci. Eng. C. 39, 161-167 (2014).

8. Li, P., Dai, Y., Zhang, J., Wang, A. \& Wei, Q. Chitosan-alginate nanoparticles as novel drug delivery system for Nifedipine. Int. J. Biomedi Sci. 4(3), 221-228 (2008).

9. Cui-Yun, Y. et al. Sustained release of antineoplastic drugs from chitosan-reinforced alginate microparticle drug delivery systems. Int. J. Pharm. 357, 15-21 (2008).

10. Giovanna, R. et al. Composite chitosan/alginate hydrogel for controlled release of deferoxamine: A system to potentially treat iron deregulation diseases. Carbohyd Polym. 136, 1338-1347 (2016).

11. Settapon, B., Pornchai, R. \& Pranee, R. Effects of preparation parameters on the characteristic of chitosan-alginate nanoparticles containing curcumin diethyl disuccinate. J. Drug. Deliv. Sci. Technol. 28, 64-72 (2015).

12. Fangfang, N. et al. Uniform chitosan-coated alginate particles as emulsifiers for preparation of stable Pickering emulsions with stimulus dependence. Colloids Surf, A: Physicochem. Eng. Asp. 456, 246-252 (2014).

13. Bagre, A. P., Jain, K. \& Jain, N. K. Alginate coated chitosan core shell nanoparticles for oral delivery of enoxaparin: In vitro and in vivo assessment. Int. J. Pharm. 456, 31-40 (2013).

14. Hye-Lee, K. et al. Preparation and characterization of nano-sized hydroxyapatite/alginate/chitosan composite scaffolds for bone tissue engineering. Mater. Sci. Eng. C. 54, 20-25 (2015).

15. Zheng, C. H., Gao, J. Q., Zhang, Y. P. \& Liang, W. Q. A protein delivery system: biodegradable alginate-chitosan-poly(lactic-coglycolic acid) composite microspheres. Biochem. Biophys. Res. Commun. 323, 1321-1327 (2004).

16. Yueling, Z., Wei, W., Piping, L., Lianyan, W. \& Guanghui, M. Preparation and evaluation of alginate-chitosan microspheres for oral delivery of insulin. Euro J. Phar Biophar 77, 11-19 (2011).

17. Anil, K. A. \& Willem, F. S. Chitosan-alginate multilayer beads for controlled release of ampicillin. Int. J. Pharm. 290, 45-54 (2005).

18. Ratul, D. K., Naresh, K. \& Utpal, B. Encapsulation of curcumin in alginate-chitosan-pluronic composite nanoparticles for delivery to cancer cells. Nanomed. Nanotechnol. 6, 153-160 (2010). 
19. George, P. \& Nikolaos, B. Swelling studies and in vitro release of verapamil from calcium alginate and calcium alginate-chitosan beads. Int. J. Pharm. 323, 34-42 (2006).

20. Liang, L. et al. Effect of formulation variables on in vitro release of a water-soluble drug from chitosan-sodium alginate matrix tablets. Asia J. Pharm. Sci. 10, 314-321 (2015).

21. Liu T., Jie J., Yu G., Chao W., Ying L. Biodegradable Alginate-Chitosan Hollow Nanospheres for codelivery of doxorubicin and paclitaxel for the effect of human lung cancer A549 cells. BioMed Res Inter 2018, Article ID 4607945, 11 pages (2018).

22. Fanf, W., Siqian, Y., Jian, Y., Quinwei, G. \& Chaobo, H. Effective method of chitosan-coated alginate nanoparticles for target drug delivery applications. J. Biomater. Appl. 31(1), 3-12 (2016).

23. Chinh, N. T. et al. Characteristics and properties of chitosan/alginate polymer blend carrying lovastatin drug. Vietnam. J. Sci. Technol. 54(2B), 118-124 (2016).

24. Hoang, T. et al. Novel drug delivery system based on ginsenoside Rb1 loaded to chitosan/alginate nanocomposite films. J. Nanosci. Nanotechnol. 19(6), 3293-3300 (2019).

25. OECD, Guidelines for the Testing of Chemicals/Section 4: Health Effects Test No. 423: Acute Oral toxicity - Acute Toxic Class Method. Organization for Economic Cooperation and Development, Paris, France (2002).

26. OECD, Repeated dose oral toxicity test method. In: OECD Guidelines for testing of chemicals, $\mathrm{N}^{\circ} 407$. Organization for Economic Cooperation and Development, Paris, France (2008)

27. Jingjun, H., Rodney, J. W. \& Joseph, B. S. Drug-polymer interaction and its significance on the physical stability of nifedipine amorphous dispersion in microparticles of an ammonio methacrylate copolymer and ethylcellulose binary blend. J. Pharm. Sci. 97, 251-262 (2008).

28. Jingjun, H., Rodney, J. W., Catherine, M. B. \& Joseph, B. S. Nifedipine solid dispersion in microparticles of ammonio methacrylate copolymer and ethylcellulose binary blend for controlled drug delivery: Effect of drug loading on release kinetics. Int. J. Pharm. 319, 44-54 (2006).

29. Mohy Eldin, M. S. et al. Oval smart pH sensitive chitosan grafted alginate hydrogel microcapsules for oral protein delivery: I. preparation and characterization. Int. J. Pharm. Pharm Sci. 7(10), 331 (2015).

30. Venkatesan, J., Bhatnagar, I. \& Kim, S. K. Chitosan-alginate biocomposite containing fucoidan for bone tissue engineering. Mar. Drugs 12(1), 300-316 (2014).

31. Dev, A. et al. Preparation of poly(lactic acid)/chitosan nanoparticles for anti-HIV drug delivery applications. Carbohyd Polym. 80, $833(2010)$.

32. Diener, W., Mischke, U., Kayser, D. \& Schlede, E. The biometric evaluation of the OECD modified version of the acute toxic class method (oral). Arch. Toxico 69, 729-734 (1995).

33. Endo, A. \& Monacolin, K. A new hypocholesterolemic agent produced by a Monascus species. J. Antibiotics 32, 852-854 (1979).

34. Jadhav, S. B., Narayana Murthy, P. S., Singh, M. M. \& Jain, G. K. Distribution of lovastatin to bone and its effect on bone turnover in rats. J. Pharm. Pharmacol. 58, 1451-1458 (2006).

\section{Acknowledgements}

The authors would like to thank the National Foundation for Science and Technology Development in Vietnam for financial support (subject code 104.02-2017.17, period 2017-2020).

\section{Author contributions}

Hoang Thai, Chinh Thuy Nguyen and Lam Dai Tran wrote the Abstract, Introduction, Methods (2.1-2.5), Results and discussion (3.1-3.6), and Conclusion. Quan Van Le and Mao Van Can wrote the Methods (2.6), Results and discussion $(3.7,3.8)$, prepared Figures 13, 14 and Tables 5-8. Loc Thi Thach, Giang Duc Le and Giang Long Bach prepared Figures 1-6. Mai Thi Tran, Huynh Duc Mai and Trang Thi Thu Nguyen prepared Tables 1-3 and Figures 7-11. Kavitha Ramadass and C.I. Sathish revised English whole manuscript and prepared Fig. 12 and Table 4.

\section{Competing interests}

The authors declare no competing interests.

\section{Additional information}

Correspondence and requests for materials should be addressed to H.T. or Q.V.L.

Reprints and permissions information is available at www.nature.com/reprints.

Publisher's note Springer Nature remains neutral with regard to jurisdictional claims in published maps and institutional affiliations.

(c) (i) Open Access This article is licensed under a Creative Commons Attribution 4.0 International cc. License, which permits use, sharing, adaptation, distribution and reproduction in any medium or format, as long as you give appropriate credit to the original author(s) and the source, provide a link to the Creative Commons license, and indicate if changes were made. The images or other third party material in this article are included in the article's Creative Commons license, unless indicated otherwise in a credit line to the material. If material is not included in the article's Creative Commons license and your intended use is not permitted by statutory regulation or exceeds the permitted use, you will need to obtain permission directly from the copyright holder. To view a copy of this license, visit http://creativecommons.org/licenses/by/4.0/.

(C) The Author(s) 2020 